\title{
Pruritus, CTCAE
}

National Cancer Institute

\section{Source}

National Cancer Institute. Pruritus, CT CAE. NCI Thesaurus. Code C58006.

A disorder characterized by an intense itching sensation. 